\title{
A New Width Measurement Method of the Stress Relief Zone on Roadway Surrounding Rocks
}

\author{
Pengfei Cui, ${ }^{1}$ Banghua Yao $\mathbb{D}^{1,2,3}$ Yong Liu $\mathbb{D}^{1,2,3}$ Jianping Wei $\mathbb{D}^{1,2,3}$ Zhihui Wen, $^{1,3}$ \\ and Hui Li ${ }^{1}$ \\ ${ }^{1}$ State Key Laboratory Cultivation Base for Gas Geology and Gas Control (Henan Polytechnic University), Jiaozuo 454000, China \\ ${ }^{2}$ School of Safety Science and Engineering, Henan Polytechnic University, Jiaozuo, Henan 454000, China \\ ${ }^{3}$ Collaborative Innovation Center of Coal Safety Work and Clean Efficient Utilization, Jiaozuo 454000, China
}

Correspondence should be addressed to Banghua Yao; yaobanghua@126.com and Yong Liu; yoonliu@126.com

Received 11 April 2019; Revised 1 August 2019; Accepted 6 November 2019; Published 27 November 2019

Academic Editor: Mohammad Sarmadivaleh

Copyright (C) 2019 Pengfei Cui et al. This is an open access article distributed under the Creative Commons Attribution License, which permits unrestricted use, distribution, and reproduction in any medium, provided the original work is properly cited.

\begin{abstract}
Determining the width of the stress relief zone on roadway surrounding rocks is the premise to optimize drilling borehole effect and increase gas extraction efficiency. In this study, a new width measurement method of the stress relief zone on the roadway surrounding rocks was proposed, which determined the width according to gas pressure attenuation speeds in roadway boreholes at different depths. Then, the variation curve of the gas pressure in boreholes at different depths with the time was gained through a field test. On this basis, laws of the gas pressure attenuation and the gas transmission and loss in boreholes at different depths were explored through a numerical simulation based on COMSOL Multiphysics, thus concluding the stress on roadway surrounding rocks, the distribution of plastic zones, and the stress-permeability relation. The scientificity of the proposed method was illustrated theoretically. Finally, the proposed method was verified by the field test data and numerical simulation results of the gas extraction at different sealing depths. Research results demonstrate that the pressure in boreholes attenuates in the logarithmic function pattern. The attenuation speed decreases with the increase of the drilling depth. The width of the stress relief zone on roadway surrounding rocks in the studied area was determined to be about $11 \mathrm{~m}$ according to the proposed method. Both the numerical simulation and the field test of the gas extraction efficiency prove the feasibility and validity of the proposed method in determining the sealing depth of the borehole for the gas extraction. Research conclusions are of important significance to enrich width measurement methods of the stress relief zone on roadway surrounding rocks and to optimize sealing parameters of underground boreholes for gas extraction.
\end{abstract}

\section{Introduction}

Coal mining in China tends to be accompanied with serious coal-gas outburst accidents. Moreover, the large-scaled development and utilization of coal resources bring a series of environmental problems, such as the atmospheric pollution and greenhouse effect. Gas is the high-quality, high-efficiency, and low-carbon clean gas energy that is accompanied with coal. The high-efficiency exploitation and utilization of the gas in coal seams have especially important significance to improve the energy consumption structure, promote the sustainable development of the environmental protection, and assure the security production of coal mines in China $[1,2]$.
The gas extraction through underground boreholes in coal mines is an important technological measure for the exploitation and use of the gas in coal seams. However, the gas extraction is challenged by prominent gas leakage, accompanied with a small flow rate and a low gas extraction concentration [3]. These problems are the consequence of poor solutions to sealing quality problems in extraction boreholes. The sealing depth is often determined according to experiences during the borehole extraction. On the one hand, the unreasonable sealing depth may increase sealing difficulties and sealing costs. On the other hand, it will form a loop between the air and the borehole in the roadway through mining-induced fractures, which decreases the gas extraction concentration [4]. Therefore, how to determine a reasonable 
sealing depth for the gas extraction is an important premise to improve the sealing quality and the gas extraction efficiency [5]. In terms of determination of reasonable sealing depth in gas extraction, some researchers studied the problem through theoretical analysis and numerical simulation. For example, the failure mode of in-seam CMM drainage boreholes and the fracture characteristics of the coal surrounding a roadway were analyzed using a viscoelastic plastic model while considering the plastic softening and dilatancy, and the proper sealing depth of an in-seam borehole was studied based on the theoretical findings [6]. A method is proposed to study the roadway geological conditions in the coal seam by monitoring the response of the idle pressure of the hydraulic motor while drilling the boreholes, and using numerical analysis, the reasonable sealing depth should be several meters larger than the stress concentration area, which is indicated in practice by the idle pressure [7, 8]. Zhao and Pan analyzed the migration law of gas seepage along the boreholes for gas extraction and the coal wall of roadways and determined the reasonable hole-sealing depth of boreholes for gas extraction by using numerical simulation [9].

Currently, relevant studies all pointed out that the sealing depth for the gas extraction should be higher than the width of the stress relief zone beside the roadway [7, 10]. Hence, determining the width of the stress relief zone beside the roadway is the premise to determine the reasonable sealing depth of boreholes. Chinese and foreign scholars proposed some field measurement methods to determine the width of the roadway stress relief zone [11]. Among these methods, the drilling index method, gas content test method, and gas extraction parameter method are widely applied [12, 13]. All of these methods reflect the degree of the coal fragmentation according to the gas content and drilling content on surrounding rocks, thus determining the width of the stress relief zone beside the roadway. However, these methods have low efficiency and accuracy due to the high sensitivity to multiple factors in the test process. In addition, geophysical exploration methods are widely used to determine the width of the stress relief zone. For example, Frid [14] tested the stress relief intensity of coal rocks in front of different coal faces by using an antenna with a resonant frequency of $100 \mathrm{kHz}$. Sa et al. [15] determined the width of the stress relief zone beside the roadway by testing changes of the electromagnetic radiation intensity in the drilling process. The acoustic wave monitoring method accompanied by a nonmetallic ultrasonic detector was applied to investigate the stress relief zone of the roadway in coal mines [16-19]. However, these methods reflect the stress relief intensity of the coal mass indirectly by electromagnetic or acoustic waves but cannot quantify changes of permeability coal masses at different depths, which restrict their wide applications. Recently, some scholars have investigated and determined the width of the stress relief zone on roadway surrounding rocks according to changes of extraction parameters at different sealing depths. Nevertheless, this method often requires a long-term observation of the gas extraction concentration in boreholes and cannot test the width of the stress relief zone quickly.
To overcome shortages of existing technologies, in this study, a new width measurement method of the stress relief zone on roadway surrounding rocks was proposed based on the analysis of relationships among stress states, fracture distributions, and the permeability of surrounding rocks, which was called as the pressure attenuation method. First, according to this method, the variation curve of the gas pressure in boreholes at different depths with time was gained through a field test, which was conducive to disclose the width range of the stress relief zone. Subsequently, laws of the gas pressure attenuation and the gas transmission and loss in boreholes at different depths were studied through a numerical simulation of COMSOL Multiphysics by combining engineering geological conditions in the studied mining area. The stress of coals beside the roadway, the distribution pattern of plastic zones, and stress-permeability relations were discussed at the same time. Moreover, the scientificity of the proposed method was illustrated theoretically, and the sealing depth of the borehole for the consequent gas extraction on roadway surrounding rocks was determined based on the analysis of the width of the stress relief zone. Finally, the field test results on the gas extraction efficiency under different sealing depths were presented.

\section{Principle and Technology of the Pressure Attenuation Method}

2.1. Test Principle. Researches demonstrated that stresses on surrounding rocks will be redistributed after the roadway excavation [20-22]. Surrounding rocks can be divided into the stress relief zone, the stress concentration zone, and the original stress zone according to the final stress state (Figure 1). In the stress relief zone, coal masses were destroyed due to the stress concentration effect, resulting in the reduction of the strength, the full fracture development, and the significant increase of the gas permeability. The stress relief zone is also called the complete seepage zone [23]. Since the intensity of the coal mass is decreased in the stress relief zone, the concentrated stress transfers to deep coal masses in the stress relief zone, forming a stress concentration zone. The stress concentration zone can be further divided into the prepeak plastic zone and the postpeak elastic zone according to stress paths. The prepeak plastic zone develops the plastic deformation and fractures. However, fractures close gradually under the effect of the high stress, accompanied with a small increase gas permeability compared with that in the original coal mass. The prepeak plastic zone is also called the transition seepage zone. Coal mass in the postpeak elastic zone develops the elastic deformation, where pores and fissures close under the high geostress, resulting in the reduction of the permeability compared with that of the original coal mass. Therefore, the postpeak elastic zone is also called the seepage shielding zone. Deep masses in the stress concentration zone are the original stress zone. Since this original stress zone is far away from the roadway, the stress state and the permeability of the coal mass are similar to those of the coal masses without the excavation disturbance. Therefore, the fracture development of coal rocks at different depths beside the roadway is different due to the different 


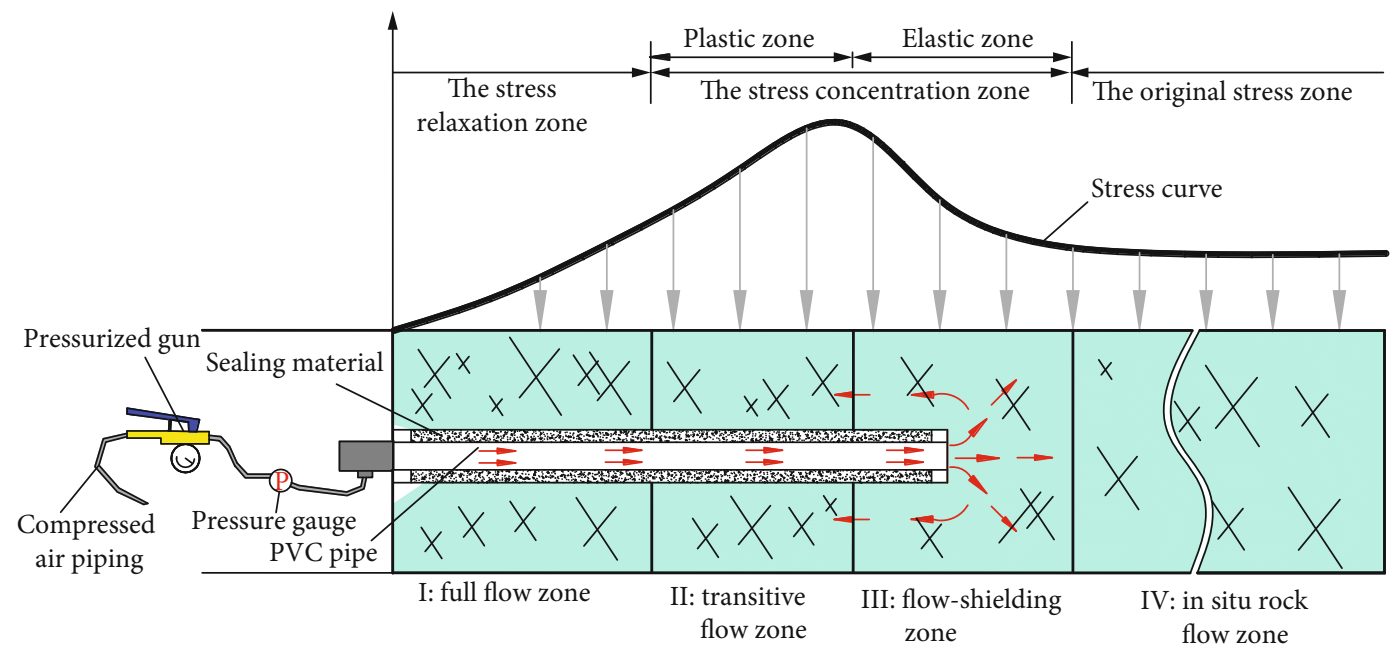

FIGURE 1: Width measurement system of stress relief zone on roadway surrounding rocks based on the pressure attenuation method.

stress paths and final stress states, which further causes a significant difference in the gas permeability of coal masses. This reflects the good relationship among the stress state, the plastic fracture development, and the gas permeability of coal masses. The pressure attenuation method characterizes the permeability of coal rocks at boreholes by testing the attenuation speed of the gas in boreholes at different depths and thereby determines the stress state of surrounding rocks as well as the width of the stress relief zone. On this basis, it provides references to determine the reasonable sealing depth of boreholes.

2.2. Test Process. The self-developed measurement system of the stress relief zone width on roadway surrounding rocks is shown in Figure 2. Based on this system, the field processing steps of the pressure attenuation method are as follows (Figure 3): (1) Select the base point for the test. (2) The borehole $1 \#$ was drilled on the coal wall vertically at about $100 \mathrm{~m}$ below the base point. The depth of this borehole was $\mathrm{Lm}$. Later, a $(L+0.2) \mathrm{m}$ long PVC tube ( $\mathrm{Lm}$ in the tube and $0.2 \mathrm{~m}$ preserved out of the tube) was put in, and then, the borehole was sealed up. (3) The PVC tube was connected with the pressurized gun. One end of the pressurized gun was connected with the pressure ventilation pipe. (4) The sealing agent was foamed and solidified for $0.5 \mathrm{~h}$. Later, the pressurized gun was started to inject $0.2 \mathrm{MPa}$ compressed air into the borehole. (5) Changes of pressure, which is read by the pressure meter on the pressurized gun, were observed for more than $0.5 \mathrm{~h}$ continuously. Five groups of the data were observed at each borehole. (6) The borehole 2\# (depth $=L+1 \mathrm{~m}$ ) was constructed at $15 \mathrm{~m}$ upwind away to borehole 1\#; the follow-up steps were performed, the same as those in borehole 1\#. The gas-injection test system is shown in Figure 1.

\section{Field Application of the Proposed Gas Attenuation Method}

3.1. Introduction to the Project. The mine of Henan Baoyushan Coal Co., Ltd. was in the border of Ruyang, Linru,

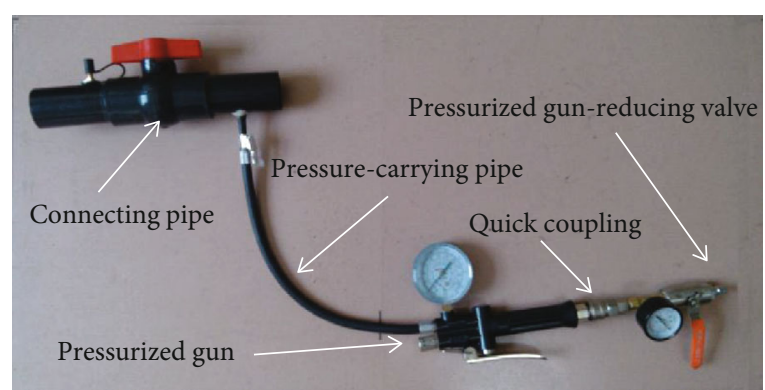

Figure 2: Assembly structure of test devices.

and Yichuan counties in Henan Province. Currently, the primary coal seams under exploitation in this mine were the 2-1 and 1-7 coal seams of the Shanxi Formation. The designed annual production capacity was 600,000 tons. The single level up and down the mixed exploitation of inclined and vertical shafts was applied in this mine. The primary and auxiliary shafts and the new air shaft were vertical ones, while the old air shaft was an inclined one. The full-seam mining along the bottom and caving roofs was employed in all shafts.

According to the geological report of Baoyushan Mine, the 2-1 coal seam was below the Shanxi Formation. The available coal content was $81 \%$ and the coal thickness ranges $0 \sim 12.78 \mathrm{~m}$, averaging at $4.02 \mathrm{~m}$. The average ash content, volatile content, and water content in the raw coal were $15.91 \%$, $14.72 \%$, and $0.83 \%$, indicating the low intensity of coal masses. The gas content in the 2-1 coal seam was closely related with the thickness of the coal seam. It is generally positively related with the thickness of the coal seam. In view of the gas emission rate of mines, the absolute and relative gas emission rates were relatively small.

The roof of the 2-1 coal seam is mainly composed of the sandstone and sandy mudstone. However, the floor is dominated by the mudstone and sandy mudstone. For the sandstone, they have large shear, tensile, and compressive strengths and their stability is good. For the mudstone and sandy mudstone, the rock resistance shear, compression, and tensile strengths are relatively low. Overall, it is generally 


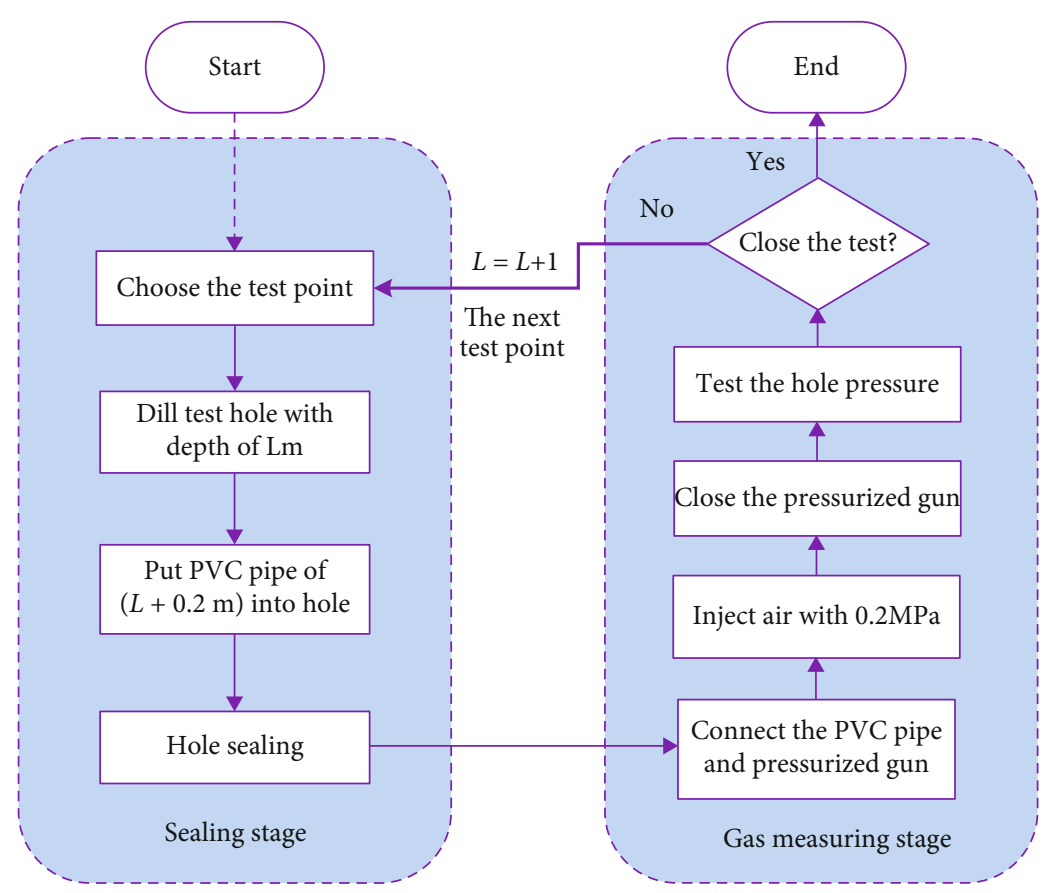

Figure 3: Test process of the gas attenuation method.

evaluated as a moderately stable roof and floor. The comprehensive column diagram of the coal seam is shown in Figure 4.

Based on the above experimental equipment and methods for measuring the width of the stress relief zone beside the roadway based on the gas pressure attenuation, a field test was carried out at the 2-1 coal seam from $100 \mathrm{~m}$ to $200 \mathrm{~m}$ of the lower crossheading 12105 in the Baoyushan Mine. Depths of boreholes 1\#-8\# were set $5 \mathrm{~m}, 6 \mathrm{~m}, 7 \mathrm{~m}$, $8 \mathrm{~m}, 9 \mathrm{~m}, 10 \mathrm{~m}, 11 \mathrm{~m}, 12 \mathrm{~m}$, and $14 \mathrm{~m}$ on the middle of the coal wall in the roadway. The pore diameter was $100 \mathrm{~mm}$ and the borehole interval was $15 \mathrm{~m}$. The layout of boreholes is shown in Figure 5.

3.2. Test Results. The variation curve of the gas pressure with the time was gained by testing the gas pressure attenuation time and its weighted average in boreholes at different depths (Figure 6). Clearly, the pressure in boreholes attenuates in the logarithmic functional pattern. The pressure attenuation is decelerated with the increase of the depth of boreholes. The time for the gas pressure in boreholes at different depths attenuating from $0.2 \mathrm{MPa}$ to $0.04 \mathrm{MPa}$ is shown in Figure 7 . Clearly, the gas pressure attenuation time is prolonged significantly when the depth of boreholes increases from $10 \mathrm{~m}$ to $11 \mathrm{~m}$. According to the above relation among the stress state, fracture development, and gas permeability coefficient on surrounding rocks beside the roadway, the width of the stress relief zone beside the roadway is preliminarily about $11 \mathrm{~m}$.

\section{Numerical Simulation of Gas Pressure Attenuation Laws in Boreholes}

It is neither possible to analyze laws of the gas leakage and loss in boreholes at different depths accurately through the

\begin{tabular}{|c|c|c|c|}
\hline Formation & Lithology & Thickness & Description \\
\hline \multirow{5}{*}{ Shanxi } & & $37.71 \mathrm{~m}$ & $\begin{array}{l}\text { Sandy mudstone } \\
\text { and siltstone }\end{array}$ \\
\hline & & $8.16 \mathrm{~m}$ & $\begin{array}{l}\text { Medium and } \\
\text { sandy mudstone }\end{array}$ \\
\hline & & $19.39 \mathrm{~m}$ & $\begin{array}{c}\text { Medium and fine } \\
\text { sand }\end{array}$ \\
\hline & & $4.02 \mathrm{~m}$ & $2^{-1}$ coal seam \\
\hline & & $3.55 \mathrm{~m}$ & Mudstone \\
\hline \multirow{4}{*}{ Taiyuan } & & $23.21 \mathrm{~m}$ & $\begin{array}{l}\text { Limestone and } \\
\text { sandy mudstone }\end{array}$ \\
\hline & & $0.72 \mathrm{~m}$ & $1^{-7}$ coal seam \\
\hline & & $11.47 \mathrm{~m}$ & Mudstone \\
\hline & & $0.26 \mathrm{~m}$ & $1^{-6}$ coal seam \\
\hline
\end{tabular}

FIGURE 4: Comprehensive column diagrams of coal rocks.

above field test nor able to give a quantitative analysis on the stress state and fracture distribution characteristics on surrounding rocks. To analyze the feasibility of the proposed method, a numerical simulation on laws of the gas transmission and loss as well as gas pressure attenuation characteristics in boreholes at different depths was carried out by using COMSOL based on the engineering geological data. COMSOL is a multiphysical field coupling software. Research results laid foundations to theoretically prove the reasonability of the proposed method. 


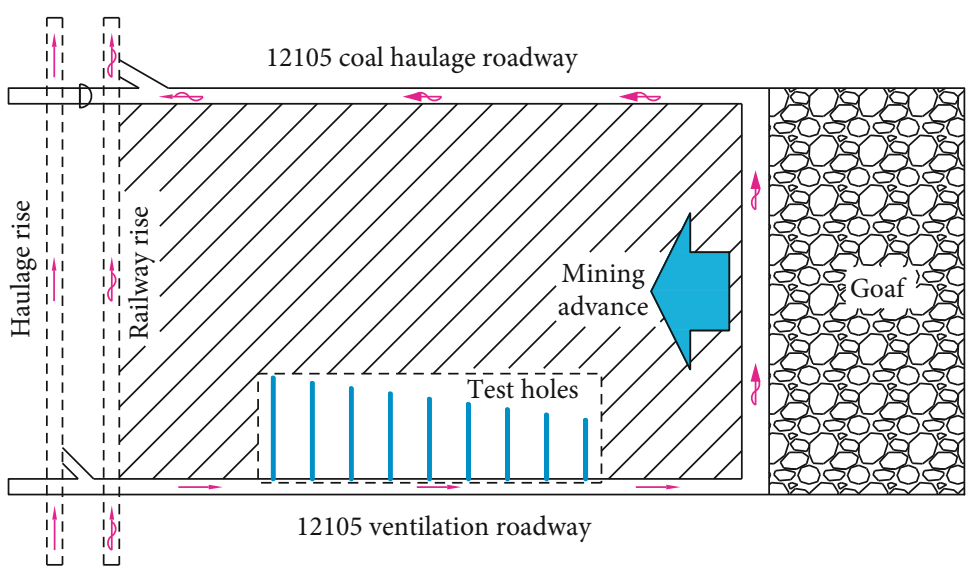

FIGURE 5: Layout profile of boreholes.

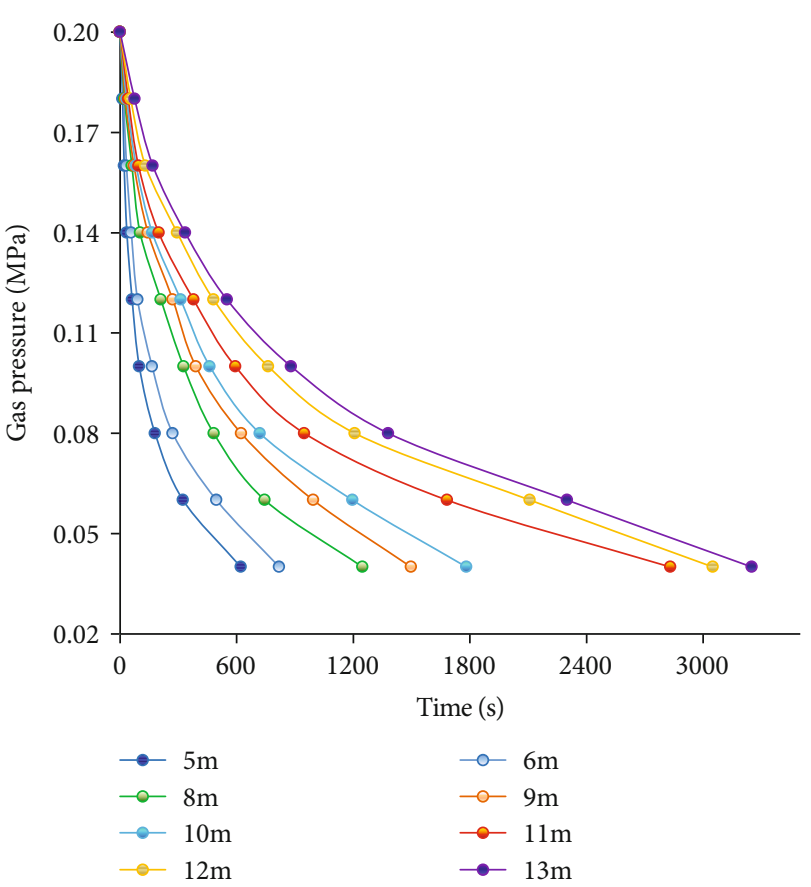

FIGURE 6: Gas pressure change as time in boreholes at different depths.

\subsection{Basic Equation of the Numerical Simulation}

4.1.1. Governing Equation of the Coal and Rock Deformation. It can be seen from the full stress-strain experiment of the coal mass that the coal mass was softened significantly after reaching the stress peak. Accordingly, the cohesion decreased continuously as a response to the softening of the coal masses. The internal frictional angle changes slightly or basically keeps constant. Therefore, the strain softening behavior of coal masses is reflected by the degradation of the cohesion. The corresponding governing equation of the coal deformation is [24]

$$
c= \begin{cases}c_{0}-\frac{\left(c_{0}-c_{r}\right) \gamma^{p}}{\gamma^{p *}}, & 0<\gamma^{p}<\gamma^{p *}, \\ c_{r}, & \gamma^{p} \geq \gamma^{p *},\end{cases}
$$

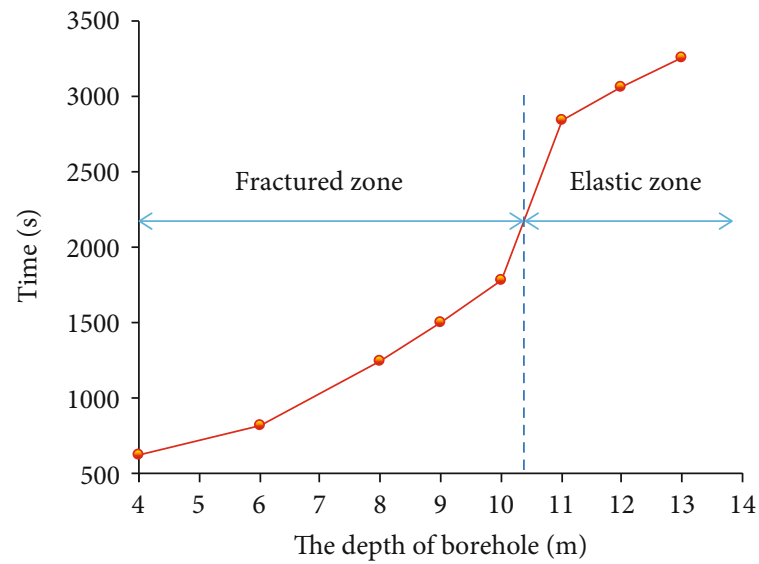

Figure 7: Time for gas pressure attenuation to $0.04 \mathrm{MPa}$ in boreholes at different depths.

where $c_{0}$ is the cohesion at peak, $c_{r}$ is the value of the mechanical parameter in the residual flow stage, $\gamma^{p}$ is the plastic deformation modulus of the softening parameter, and $\gamma^{p *}$ is the plastic deformation modulus of the residual flow in the initial softening stage. The equivalent plastic strain $\left(\gamma^{p}\right)$ can be expressed as

$$
\gamma^{p}=\sqrt{\frac{2}{3}\left(\varepsilon_{1}^{p} \varepsilon_{1}^{p}+\varepsilon_{2}^{p} \varepsilon_{2}^{p}+\varepsilon_{3}^{p} \varepsilon_{3}^{p}\right)},
$$

where $\varepsilon_{1}^{p}, \varepsilon_{2}^{p}$, and $\varepsilon_{3}^{p}$ are principal plastic strains. In the experiment, it is tested that $\gamma^{p *}$ is 0.04 .

The yield failure of the coal mass can be characterized by the maximum tension stress criterion and the MohrCoulomb criterion (positive for tension stress). It can be expressed as

$$
\begin{aligned}
& F_{1}=\sigma_{3}-\sigma_{t 0}, \\
& F_{2}=\sigma_{1}-\sigma_{3} \frac{1+\sin \phi}{1-\sin \phi}-2 c \sqrt{\frac{1+\sin \phi}{1-\sin \phi}},
\end{aligned}
$$




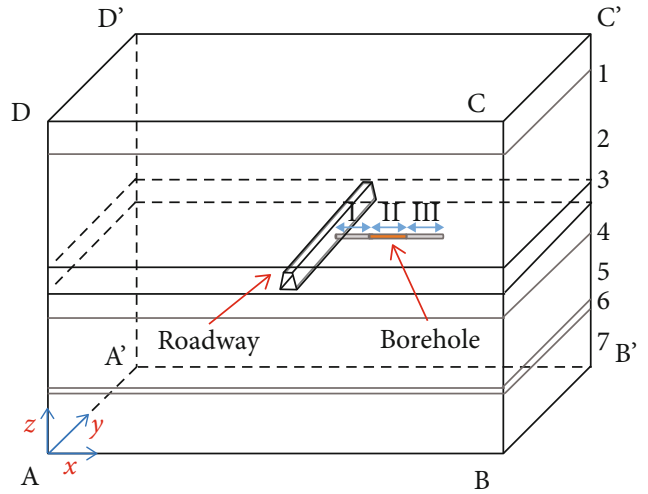

(a)

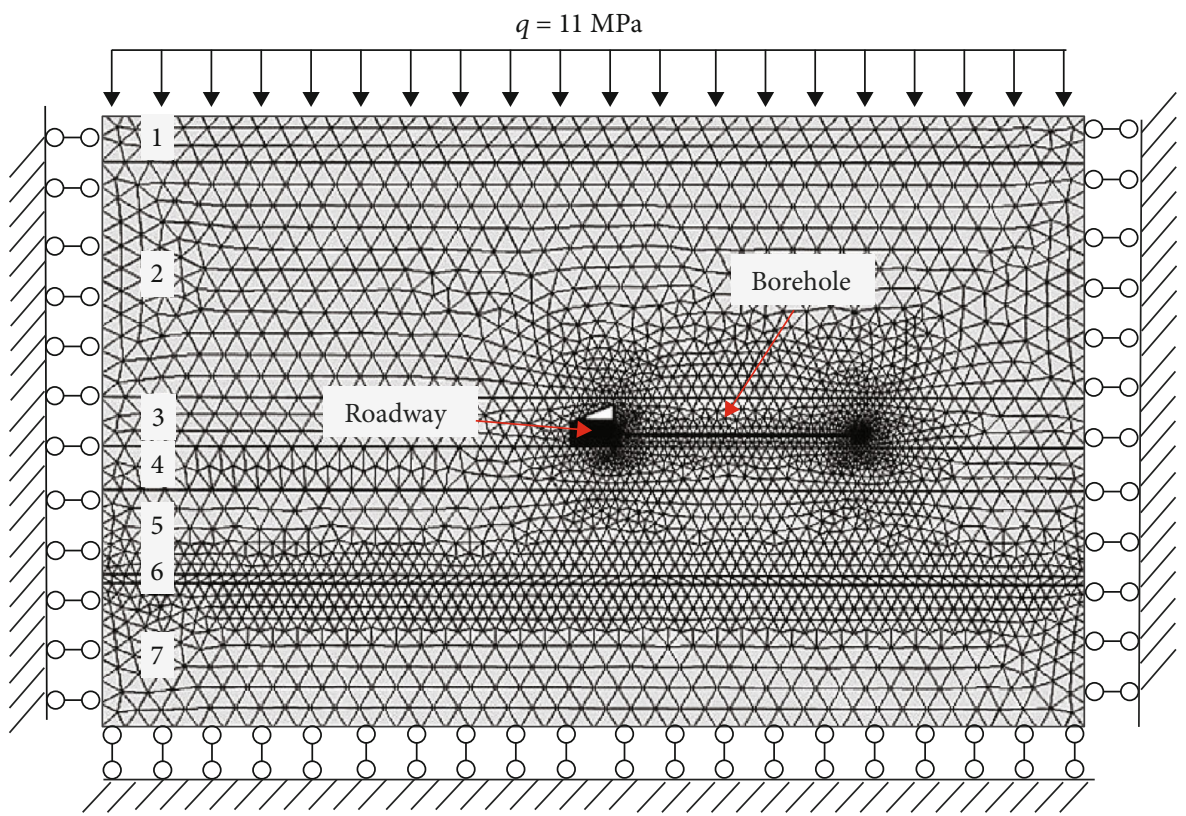

(b)

FIGURE 8: Numerical calculation model: (a) spatial schematic map; (b) grid schematic.

where $\sigma_{t 0}$ is the uniaxial tensile strength, $c$ and $\varphi$ are the cohesion and the internal frictional angle, respectively, and $F_{1}$ and $F_{2}$ are yield functions.

4.1.2. Evolution Equation of the Permeability. Under stress actions, the primary fractures close mainly before damage of the coal mass, which leads to the permeability reduction to some extent. With the increase of the stress of the coal mass, internal fractures are expanded and connected, which further increase the permeability of the coal mass. Based on the stress-damage-seepage model of the coal mass in existing studies, the evolution equation of the permeability with considerations to the softening of coal masses was gained through analysis $[25,26]$ :

$$
k= \begin{cases}\left(1+\frac{\gamma^{p}}{\gamma^{p *}} \cdot \xi\right) \exp \left[b_{\sigma}(\Delta \Theta)\right] k_{0}, & 0<\gamma^{p}<\gamma^{p *}, \\ (1+\xi) \exp \left[b_{\sigma}(\Delta \Theta)\right] k_{0}, & \gamma^{p} \geq \gamma^{p *},\end{cases}
$$

where $\xi$ is the rush coefficient of the permeability and it is 20 in this study. $\Theta=\left(\sigma_{1}+\sigma_{2}+\sigma_{3}\right) / 3$ is the effective stress, where $\sigma_{1}, \sigma_{2}$, and $\sigma_{3}$ are primary, secondary, and third principal stresses, respectively. $b_{\sigma}$ is the fitting constant in the experiment, which is generally 0.2 .

4.1.3. Governing Equation of the Gas Flow. Based on the working principle of the proposed pressure attenuation method, gas firstly makes pipe flow in boreholes and then seepages into coal seams. The N-S equation is a governing equation that describes the fluid in pipelines [27]. It is expressed as

$\rho \frac{\partial u}{\partial t}+\eta \cdot u=\nabla \cdot\left[-p+\eta\left\{\nabla u+(\nabla u)^{T}-\frac{2 \eta}{3} \cdot \nabla u\right\}\right], \quad \Delta \cdot u=0$, 
TABLE 1: Strata structure and mechanical parameters of rocks.

\begin{tabular}{|c|c|c|c|c|c|c|c|c|c|}
\hline No. & Lithology & $\begin{array}{l}\text { Depth } \\
(\mathrm{m})\end{array}$ & $\begin{array}{l}\text { Density } \\
\left(\mathrm{kg} \cdot \mathrm{m}^{-3}\right)\end{array}$ & $\begin{array}{c}\text { Compressive } \\
\text { strength }(\mathrm{MPa})\end{array}$ & $\begin{array}{c}\text { Tensile strength } \\
(\mathrm{MPa})\end{array}$ & $\begin{array}{l}\text { Poisson } \\
\text { ratio }\end{array}$ & $\begin{array}{l}\text { Elastic modulus } \\
\qquad(\mathrm{GPa})\end{array}$ & $\begin{array}{l}\text { Friction } \\
\text { angle }\left({ }^{\circ}\right)\end{array}$ & $\begin{array}{l}\text { Cohesion } \\
\text { (MPa) }\end{array}$ \\
\hline 1 & Sandy mudstone & 4.2 & 2300 & 39 & 1.12 & 0.24 & 10 & 36 & 3.4 \\
\hline 2 & Fine sandstone & 19.0 & 2620 & 37.9 & 0.57 & 0.32 & 6 & 40.5 & 9.2 \\
\hline 3 & Coal & 4.0 & 1437 & 8 & 1.29 & 0.38 & 3 & 30 & 1.2 \\
\hline 4 & Mudstone & 3.5 & 2470 & 25.9 & 0.90 & 0.31 & 13 & 40 & 3.5 \\
\hline 5 & Limestone & 6.9 & 2800 & 30 & 0.90 & 0.23 & 11 & 37 & 2.5 \\
\hline 6 & Coal & 0.7 & 1437 & 8 & 1.29 & 0.38 & 3 & 30 & 1.2 \\
\hline 7 & Mudstone & 11.7 & 2470 & 25.9 & 0.87 & 0.31 & 13 & 31.1 & 3.5 \\
\hline
\end{tabular}

where $\rho$ is the density of the gas, $u$ is the speed of the gas, $p$ is the pressure of the gas, and $\eta$ is the viscosity coefficient of the gas.

The gas transmission law in the coal seam basically conforms to Darcy's law $[28,29]$, and it can be expressed as

$$
\frac{\partial m}{\partial t}-\nabla \cdot(\rho \vec{q})=Q_{s},
$$

where $t$ is time, $Q_{s}$ is the gas source, and $m$ is the gas mass in unit volume of the coal matrix. $\vec{q}$ is the vector of the Darcy speed. If influences of the gravity are neglected, $\vec{q}$ can be expressed as

$$
\vec{q}=-\frac{k}{\mu} \nabla p,
$$

where $k$ is the permeability and $\mu$ is the viscosity coefficient of the gas.

4.2. Construction of the Numerical Calculation Model. To explore gas leakage and loss laws during the test, a corresponding numerical calculation model was constructed considering actual geological conditions at the above test points by using COMSOL Multiphysics (Figure 8). The element type was the triangle, and the predefined mesh size was obtained by using the free mesh parameter "Fine." Mechanical parameters of the strata were obtained through rock mechanics experiment [30] and are listed in Table 1. The buried depth of the coal seam was $475 \mathrm{~m}$, and the roadway was a ladder-shaped roadway in the middle of the model, covering an area of $10 \mathrm{~m}^{2}$. The diameter and depth of the consequent borehole were about $0.1 \mathrm{~m}$ and $5 \mathrm{~m}$ $13 \mathrm{~m}$, respectively. For coal deformations, and the gas seepage, the boundary conditions are illustrated in Table 2. For initial conditions, $0.2 \mathrm{MPa}$ compressed air was stored initially in the top of boreholes. The viscosity coefficient and the density of the gas were $5 \times 10^{-5} \mathrm{~Pa} \cdot \mathrm{s}$ and $1.29 \mathrm{~kg} / \mathrm{m}^{3}$, respectively. The initial permeability of the coal seam was $4.72 \times 10^{-13} \mathrm{~m}^{2}$. Due to the long-term gas desorption and transfer in coal masses of surrounding rocks beside the roadway, the relative gas pressure was basically $0 \mathrm{MPa}$ [31].
TABLE 2: Constrain condition of the model.

\begin{tabular}{lcc}
\hline Boundary & Mechanical constraints & Seepage constraints \\
\hline ABB'A' & Fixed in the $z$ direction & Impermeable \\
CDD'C' & Free, $\sigma_{z z}=11 \mathrm{MPa}$ & Impermeable \\
ADD'A' & Fixed in the $x$ direction & Impermeable \\
BCC'B' & Fixed in the $x$ direction & Impermeable \\
A'B'C'D' & Fixed in the $y$ direction & Impermeable \\
ABCD & Fixed in the $y$ direction & Impermeable \\
Roadway & Free & $p=0 \mathrm{MPa}$ \\
Borehole I & Free & Impermeable \\
Borehole II & $/$ & uns (N-S velocity) $=$ udr \\
Borehole III & Free & (Darcy velocity) \\
\hline
\end{tabular}

4.3. Simulation Results and Analysis. After roadway excavation, the stress was redistributed (Figure 9) and there was a plastic zone in the surrounding rock (Figure 10). In Figure 9, the vertical stress displayed stress relief around the roadway, with an elliptical shape, while it showed the stress concentration about $11 \mathrm{~m}$ away from the roadway wall. In Figure 10, we could see that the plastic zone was mainly distributed around the roadway, with a range of radius of about $11 \mathrm{~m}$; in this range, there was a full development of fractures in coal rocks.

As the permeability was related to coal seam damage and stress, the permeability varied during the excavation. The distributions of stress and permeability are shown in Figure 11. Around the roadway wall, namely, $11 \mathrm{~m}$ from the wall, the coal undergoes plastic deformation and the stress is unloaded. In this area, because of the coal seam damage, the permeability of the coal element increases. Then, around 11 to $20 \mathrm{~m}$ from the roadway wall, there is a permeability reducing zone for the stress concentration in this area. Besides, the stress of the coal mass finally tends to the original stress state with the depth more than $20 \mathrm{~m}$, and the corresponding permeability finally tends to the original permeability.

The distribution cloud map of the gas pressure in boreholes at different depths when $t=3600 \mathrm{~s}$ is shown in Figure 12. With the increase of the depth of the borehole, the gas pressure decreases gradually. For example, the maximum gas pressures in boreholes are $217.943 \mathrm{~Pa}$ and 


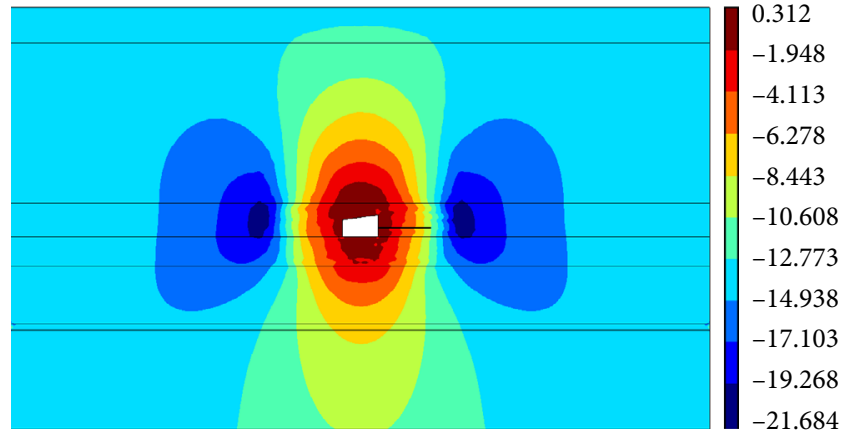

FIgURE 9: Vertical stress variation law of surrounding rock beside roadway.

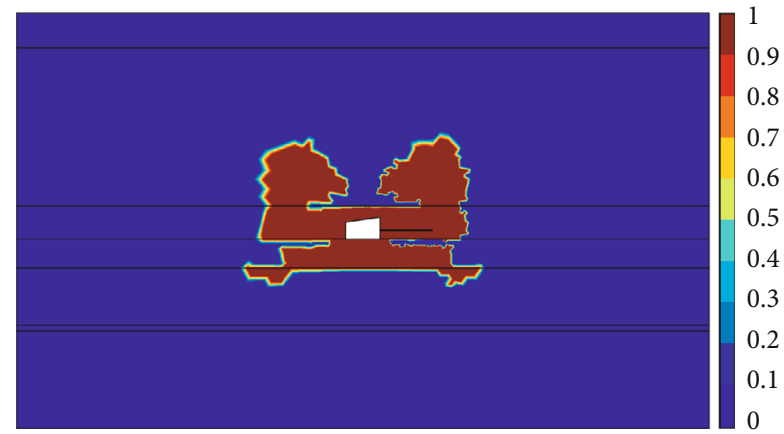

Figure 10: Distribution of plastic zone on roadway surrounding rocks.

979.556 Pa when the depth of boreholes is $5 \mathrm{~m}$ and $13 \mathrm{~m}$, respectively. When the depth of boreholes increases from $5 \mathrm{~m}$ to $13 \mathrm{~m}$, the variation curve of the gas pressure with the time is shown in Figure 13. Clearly, the gas pressure attenuation speed is high firstly and then low. It is approximately a logarithmic variation trend. The pressure attenuation speed decreases gradually as the depth of boreholes increases. The time for the pressure attenuation from $0.2 \mathrm{MPa}$ to $0.04 \mathrm{MPa}$ is increased. Additionally, the gas pressure attenuation speed changes slightly with the depth of boreholes $(<11 \mathrm{~m})$, but it decreases dramatically after $11 \mathrm{~m}$. This is because the region within $11 \mathrm{~m}$ away from the coal wall is basically in the prepeak fracture zone with high permeability. This is conducive to accelerate the pressure attenuation. The region after $11 \mathrm{~m}$ away from the coal wall is in the prepeak compaction zone or the stress zone of primary rocks, which has poor permeability. This decelerates the pressure attenuation. Simulation results can reflect the gas leakage and seepage laws in the roadway surrounding rocks intuitively, which theoretically proves the scientificity of the scope of the stress relief zone determined by the proposed pressure attenuation method.

\section{Verification of Results}

To further verify the feasibility and validity of the proposed pressure attenuation method in testing the width of the stress relief zone and determining the sealing depth for gas extraction boreholes, an engineering verification test was carried out on the crossheading of the working face 12015 in

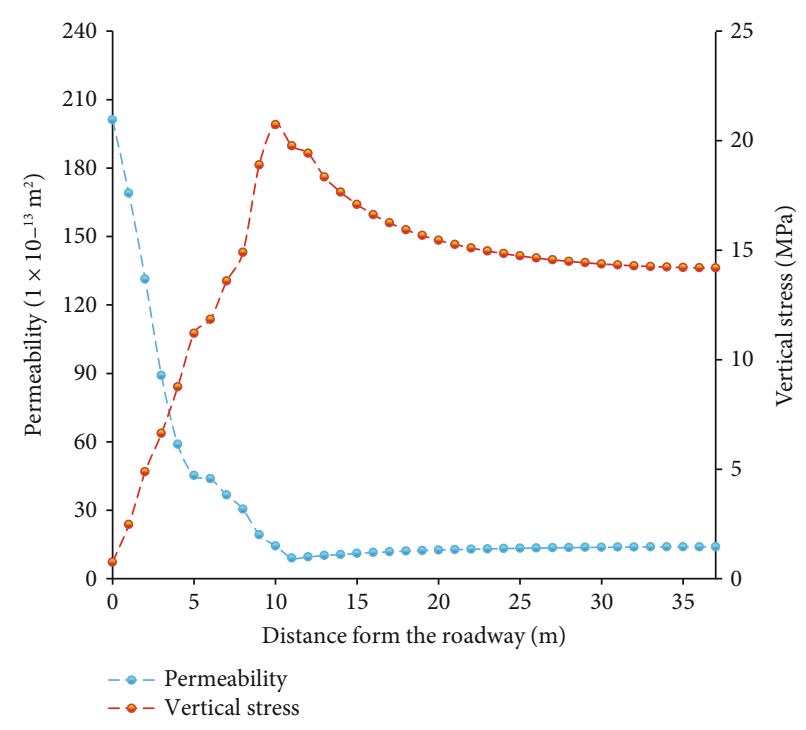

FIGURE 11: Vertical stress and permeability curves of surrounding rock.

Baoyushan Mine. A total of 6 groups of upward extraction boreholes were constructed. The diameter of these boreholes was $89 \mathrm{~mm}$ and their sealing depths were set $8 \mathrm{~m}, 9 \mathrm{~m}, 10 \mathrm{~m}$, $11 \mathrm{~m}, 12 \mathrm{~m}$ and $13 \mathrm{~m}$. All boreholes were sealed with polyurethane (PU). After finishing the borehole drilling and reasonable sealing, the extraction boreholes were connected onto the gas extraction tube by controlling the valve and gas measuring holes. Besides, they were connected into the gas monitoring system of the mine. Later, the gas extraction concentration, negative pressure, flow rate, and temperature in boreholes were monitored for one week successively, getting the average flow rate and concentration in each group of boreholes (Table 3 ).

Table 3 shows that the pure flow rate and the concentration of the gas increase gradually with the increase of the sealing depth. In particular, the gas extraction concentration is increased dramatically when the sealing depth increases from $10 \mathrm{~m}$ to $11 \mathrm{~m}$. Subsequently, the gas extraction concentration increases slightly due to the continuous increase of the sealing depth. On the one hand, this verifies the conclusion in the field test and the numerical simulation that the depth for the roadway failure is about $11 \mathrm{~m}$. On the other hand, this proves the reasonability and feasibility of the proposed pressure attenuation method in determining the width of the stress relief zone beside the roadway and the sealing depth of boreholes.

\section{Conclusions}

In this paper, a new width measurement method of the stress relief zone on the roadway surrounding rocks was proposed. The variation curve of the gas pressure in boreholes at different depths with the time was gained through a field test. Laws of the gas pressure attenuation and the gas transmission and loss in boreholes at different depths were studied through a numerical simulation of COMSOL Multiphysics by combining engineering geological conditions in the studied mining 


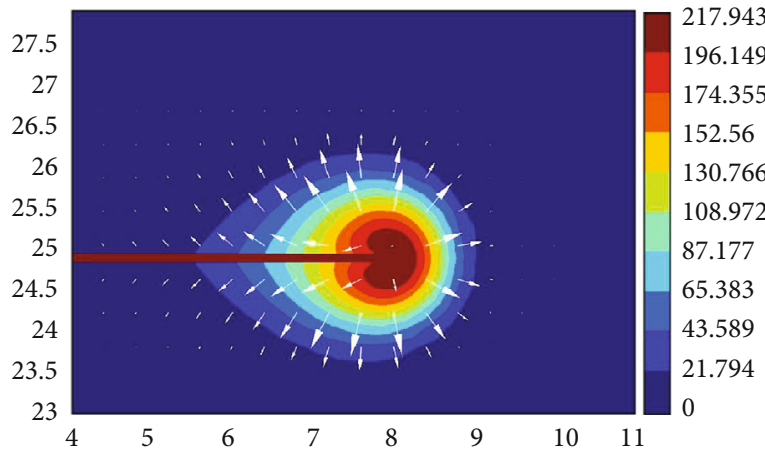

(a)

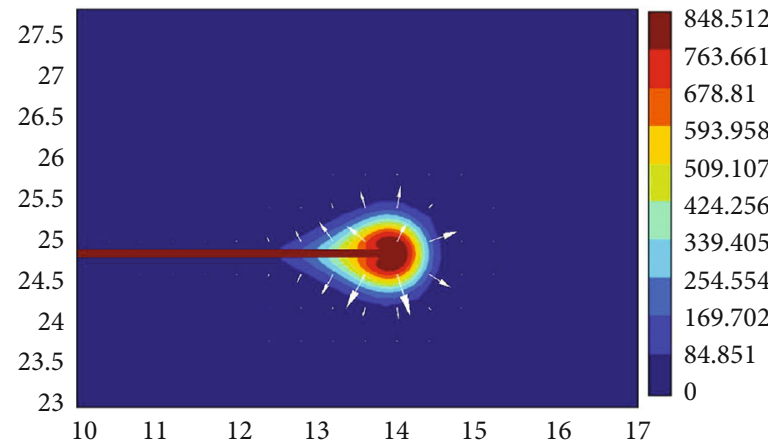

(c)

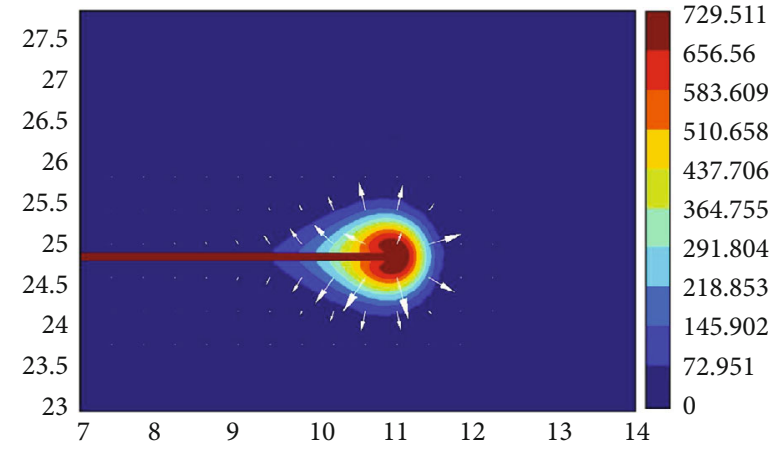

(b)

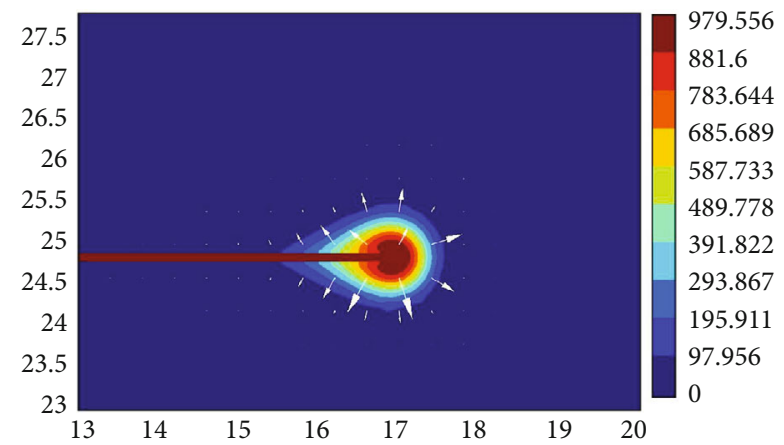

(d)

FIGURE 12: Distribution of gas pressure under different depths of boreholes when $t=3600 \mathrm{~s}$ (local): (a) the hole depth of $5 \mathrm{~m}$; (b) the hole depth of $8 \mathrm{~m}$; (c) the hole depth of $11 \mathrm{~m}$; (d) the hole depth of $13 \mathrm{~m}$.

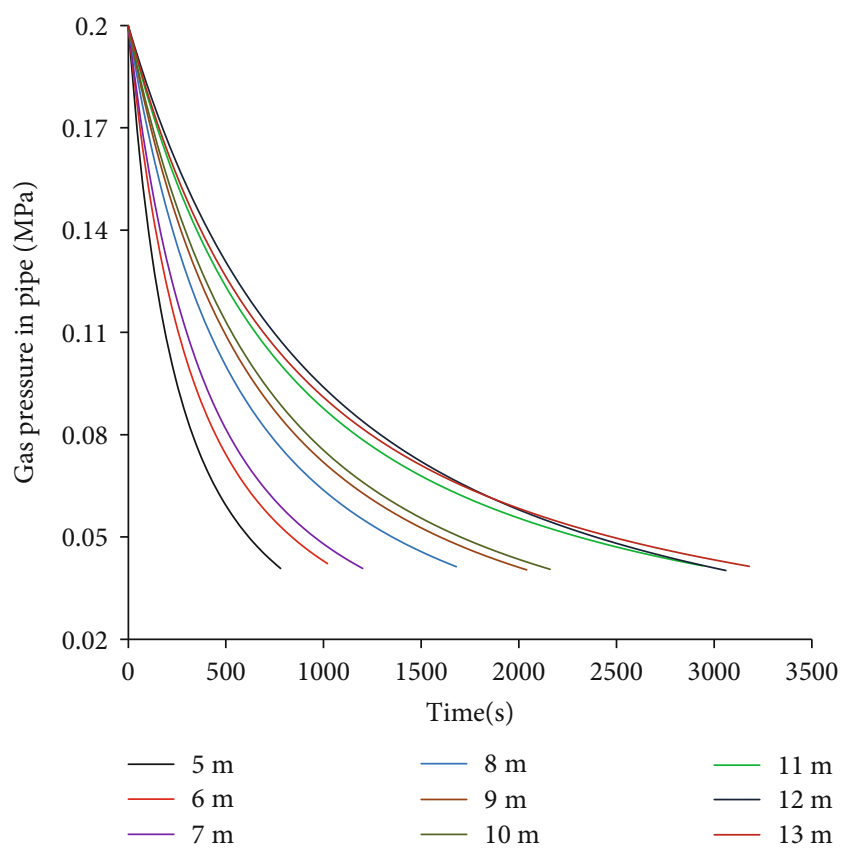

Figure 13: Pressure attenuation curves in boreholes at different depths with time.

areas. Finally, the field test on the gas extraction efficiency under different sealing depths was carried out, and some important findings have been drawn:
(1) The pressure attenuation method which is a new width measurement method of the stress relief zone is proposed based on the systematic analysis of relations among the stress state of the coal mass, fracture distributions, and the permeability coefficient in different regions of surrounding rocks. It determines the air permeability of the coal mass through a contrastive analysis of changes of the gas pressure attenuation speed in boreholes at different depths with time. On this basis, the stress state of the coal mass and the width of the stress relief zone are determined

(2) A numerical calculation model of the roadway on the work face 12015 in the Baoyushan Mine is constructed. A simulation study is carried out using COMSOL Multiphysics, which discloses distributions of the stress, plastic zone, and permeability of the roadway surrounding rocks. Gas transmission and pressure attenuation laws in surrounding rocks under different depths are analyzed. The simulation results agree well with the field test data. Both the simulation analysis and the field test conclude that the width of the stress relief zone beside the roadway in the lower crossheading of the work face 12015 in the Baoyushan Mine is about $11 \mathrm{~m}$. This theoretically verifies the scientificity of the proposed pressure attenuation method in determining the width of the stress relief zone 


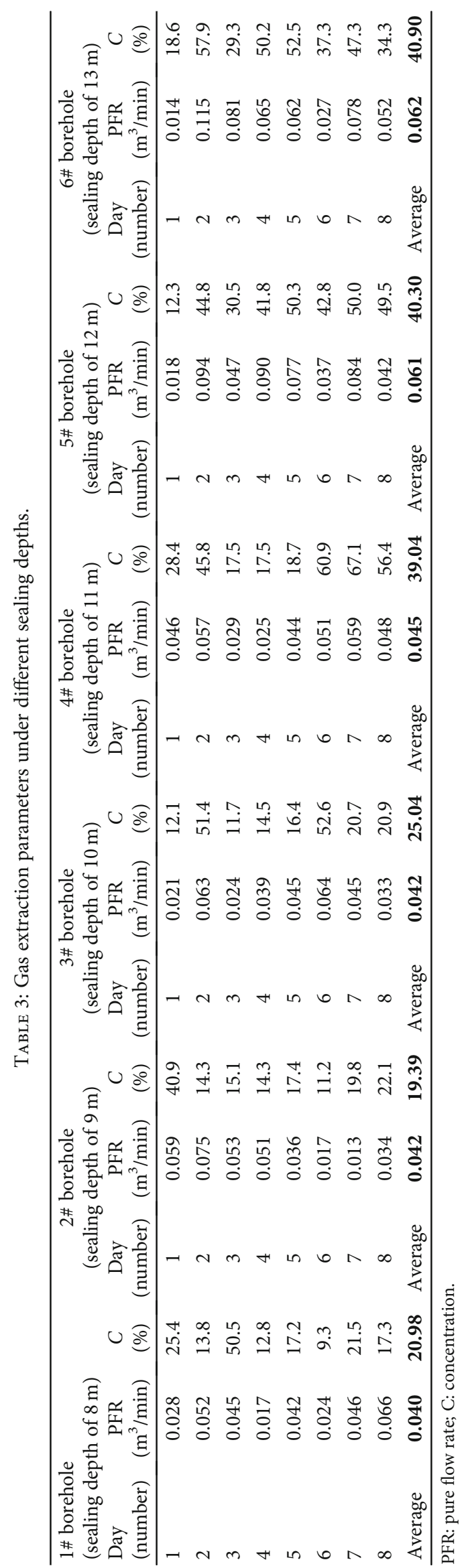


(3) The field investigation of the gas extraction efficiency under different sealing depths proves that the gas extraction concentration is increased significantly after $11 \mathrm{~m}$ of the sealing depth. This reveals that the width of the stress relief zone determined by the proposed pressure attenuation method can be used as references to determine the sealing depth of boreholes for the gas extraction

The method proposed in this work helps enhance the gas extraction efficiency by better understanding and measurement of the depth of the roadway surrounding the rock stress relief zone distribution, so that proper sealing parameters can be adopted correctly. It can also be extended to other fields such as the roadway support, the fluid flow control, and other engineering applications related to the fracture measurement.

\section{Data Availability}

The data used to support the findings of this study are included within the article.

\section{Conflicts of Interest}

The authors declare that they have no conflicts of interest.

\section{Acknowledgments}

This project is supported by the National Key R\&D Program of China (2017YFC0804207), National Natural Science Foundation of China (Nos. 51974109, 51704096, 51774110, 51774118, and U1704129), Program for Innovative Research Team in University of Ministry of Education of China (IRT_ 16R22), and Fundamental Research Funds for the University of Henan Province (NSFRF180330).

\section{References}

[1] Y. F. Wang, X. Q. He, E. Y. Wang, and Y. Z. Li, "Research progress and development tendency of the hydraulic technology for increasing the permeability of coal seams," Journal of China Coal Society, vol. 39, no. 10, pp. 1945-1955, 2014.

[2] D. Ma, H. Duan, J. Liu, X. Li, and Z. Zhou, "The role of gangue on the mitigation of mining-induced hazards and environmental pollution: an experimental investigation," Science of the Total Environment, vol. 664, pp. 436-448, 2019.

[3] T. Xia, F. Zhou, J. Liu, and F. Gao, "Evaluation of the predrained coal seam gas quality," Fuel, vol. 130, pp. 296-305, 2014.

[4] F. Q. Wei, S. P. Lian, C. Zhang, and S. B. Liu, "Study on reasonable hole-sealing-depth down the seam of Mengin mine," Journal of Henan Polytechnic University, vol. 32, no. 6, pp. 686-690, 2013.

[5] F. B. Zhou, Y. N. Sun, H. J. Li, and G. F. Yu, "Research on the theoretical model and engineering technology of the coal seam gas drainage hole sealing," Journal of China University of Mining \& Technology, vol. 45, no. 3, pp. 433-439, 2016.

[6] Q. Liu, H. Zhou, Y. Cheng, L. Shu, and B. Ullah, "An improved method for high-efficiency coal mine methane drainage: theoretical analysis and field verification," Energy Science \& Engineering, vol. 6, no. 6, pp. 739-748, 2018.

[7] K. Zhang, K. Sun, B. Yu, and R. P. Gamage, "Determination of sealing depth of in-seam boreholes for seam gas drainage based on drilling process of a drifter," Engineering Geology, vol. 210, pp. 115-123, 2016.

[8] D. Ma, M. Rezania, H. S. Yu, and H. B. Bai, "Variations of hydraulic properties of granular sandstones during water inrush: effect of small particle migration," Engineering Geology, vol. 217, pp. 61-70, 2017.

[9] D. Zhao and J. Pan, "Numerical simulation on reasonable hole-sealing depth of boreholes for gas extraction," AIP Advances, vol. 8, no. 4, 2018.

[10] J. He and K. Y. Dong, "Research on rational sealing depth of gas drainage borehole in large section roadway," China Coal, vol. 40, no. 2, pp. 101-104, 2014.

[11] D. Ma, X. Miao, H. Bai et al., "Effect of mining on shear sidewall groundwater inrush hazard caused by seepage instability of the penetrated karst collapse pillar," Natural Hazards, vol. 82, no. 1, pp. 73-93, 2016.

[12] L. Bozhang and S. Chongxing, "Determination of Reasonable Hole Sealing Depth in Gas Suction Drilling," Jiangxi Coal Science \& Technology, vol. 2, 2012.

[13] J. Jian-yu and L. Wei-yong, "Study on the Reasonable Sealing Depth of Gas Drainage Drilling in Coal Seam," Shanxi Coking Coal Science \& Technology, vol. 11, 2013.

[14] V. Frid, "Rockburst hazard forecast by electromagnetic radiation excited by rock fracture," Rock Mechanics and Rock Engineering, vol. 30, no. 4, pp. 229-236, 1997.

[15] Z. Y. SA, X. Q. HE, E. Y. WANG, and G. M. YU, “An Experimental Study of the Electromagnetic Emission Memory Effect During Deformation and Fracture of Coal or Rock," Chinese Journal of Geophysics, vol. 48, no. 2, pp. 419-426, 2005.

[16] M. Tao, Z. Hong, K. Peng, P. Sun, M. Cao, and K. du, "Evaluation of excavation-damaged zone around underground tunnels by theoretical calculation and field test methods," Energies, vol. 12, no. 9, pp. 1682-1700, 2019.

[17] H. Wang, Y. Jiang, S. Xue et al., “Assessment of excavation damaged zone around roadways under dynamic pressure induced by an active mining process," International Journal of Rock Mechanics and Mining Sciences, vol. 77, pp. 265-277, 2015.

[18] D. Ma, H. Duan, X. Li, Z. Li, Z. Zhou, and T. Li, "Effects of seepage-induced erosion on nonlinear hydraulic properties of broken red sandstones," Tunnelling and Underground Space Technology, vol. 91, p. 102993, 2019.

[19] X. G. Liu, "Study on optimization of hole sealing depth based on stress-fissure characters of surrounding rock," Safety in Coal Mines, vol. 49, no. 5, pp. 63-66, 2018.

[20] S. Hu, F. Zhou, Y. Liu, and T. Xia, "Effective stress and permeability redistributions induced by successive roadway and borehole excavations," Rock Mechanics and Rock Engineering, vol. 48, no. 1, pp. 319-332, 2015.

[21] D. Ma, J. Wang, X. Cai et al., "Effects of height/diameter ratio on failure and damage properties of granite under coupled bending and splitting deformation," Engineering Fracture Mechanics, vol. 220, no. 15, p. 106640, 2019.

[22] R. L. Zhang, Z. J. Wang, and J. W. Chen, "Experimental research on the variational characteristics of vertical stress of soft coal seam in front of mining face," Safety Science, vol. 50, no. 4, pp. 723-727, 2012. 
[23] D. Ma, X. Miao, H. Bai et al., "Impact of particle transfer on flow properties of crushed mudstones," Environmental Earth Sciences, vol. 75, no. 7, 2016.

[24] A. A. Borisenko, "Effect of gas pressure on stresses in coal strata," Soviet Mining Science, vol. 21, no. 1, pp. 88-92, 1985.

[25] F. H. An, Y. P. Cheng, W. Liang, and L. Wei, "A numerical model for outburst including the effect of adsorbed gas on coal deformation and mechanical properties," Computers and Geotechnics, vol. 54, pp. 222-231, 2013.

[26] D. R. Viete and P. G. Ranjith, "The effect of $\mathrm{CO}_{2}$ on the geomechanical and permeability behaviour of brown coal: Implications for coal seam $\mathrm{CO}_{2}$ sequestration," International Journal of Coal Geology, vol. 66, no. 3, pp. 204-216, 2006.

[27] F. H. An, Preparation and initiation of coal and gas outburst and its numerical modelling study, China University of Mining and Technology, 2014.

[28] D. Ma, J. Wang, and Z. Li, "Effect of particle erosion on mining-induced water inrush hazard of karst collapse pillar," Environmental Science and Pollution Research, vol. 26, no. 19, pp. 19719-19728, 2019.

[29] D. Ma, X. X. Miao, Y. Wu et al., "Seepage properties of crushed coal particles," Journal of Petroleum Science and Engineering, vol. 146, pp. 297-307, 2016.

[30] Baoyushan Coal Mine Company, Baoyushan geological and mineral resource exploration (BGMRE), Henan Coal Chemical Industry Group Co., Ltd, Henan, China, 2014.

[31] S. N. Zhou, "Mechanism of gas flow in coal seam," Journal of China Coal Society, vol. 15, no. 1, pp. 15-24, 1990. 

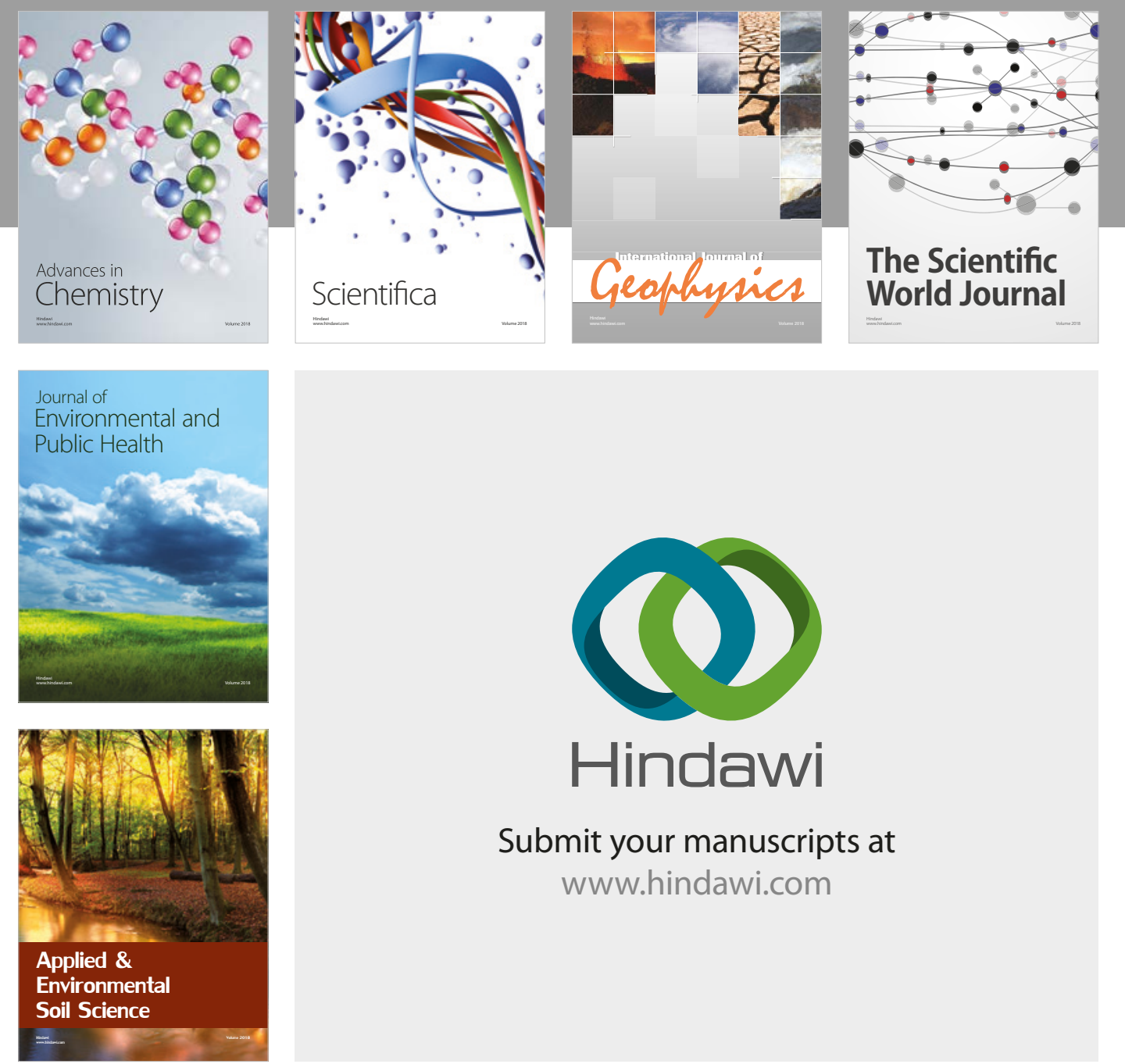

The Scientific

\section{World Journal}
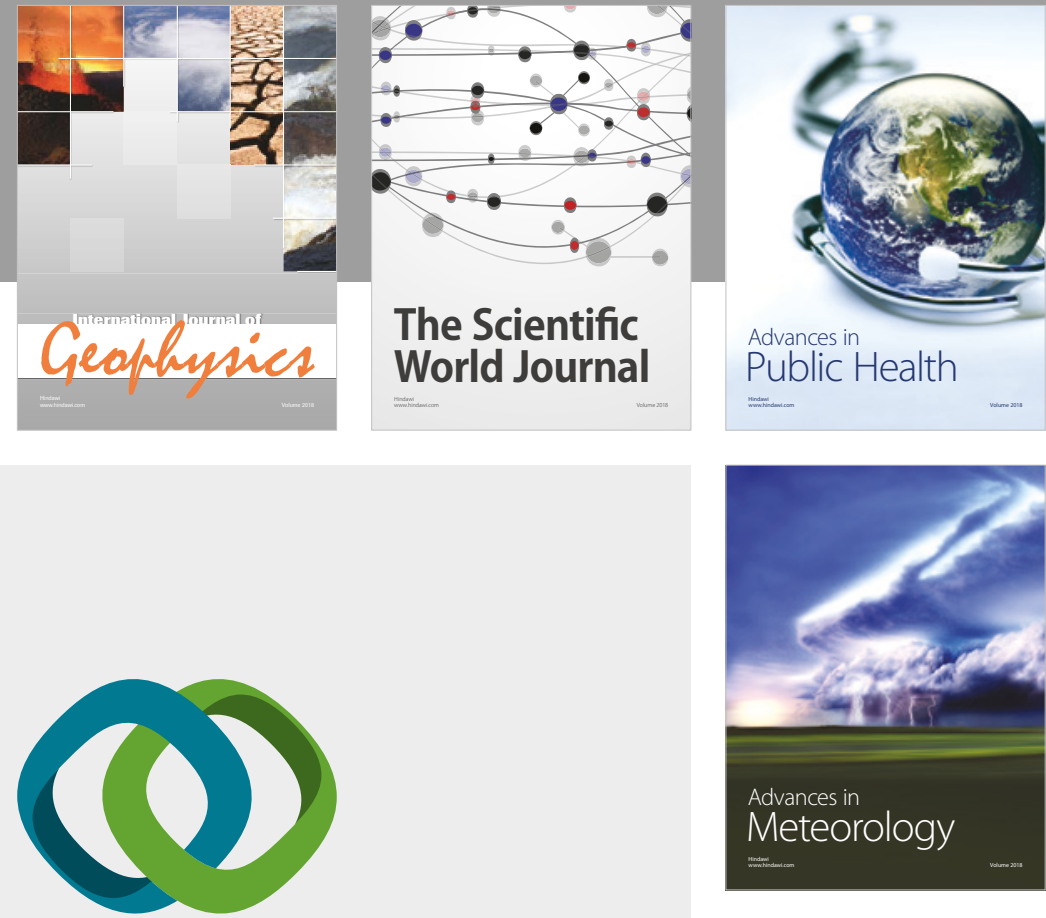

Advan

Public Health

\section{Hindawi}

Submit your manuscripts at

www.hindawi.com
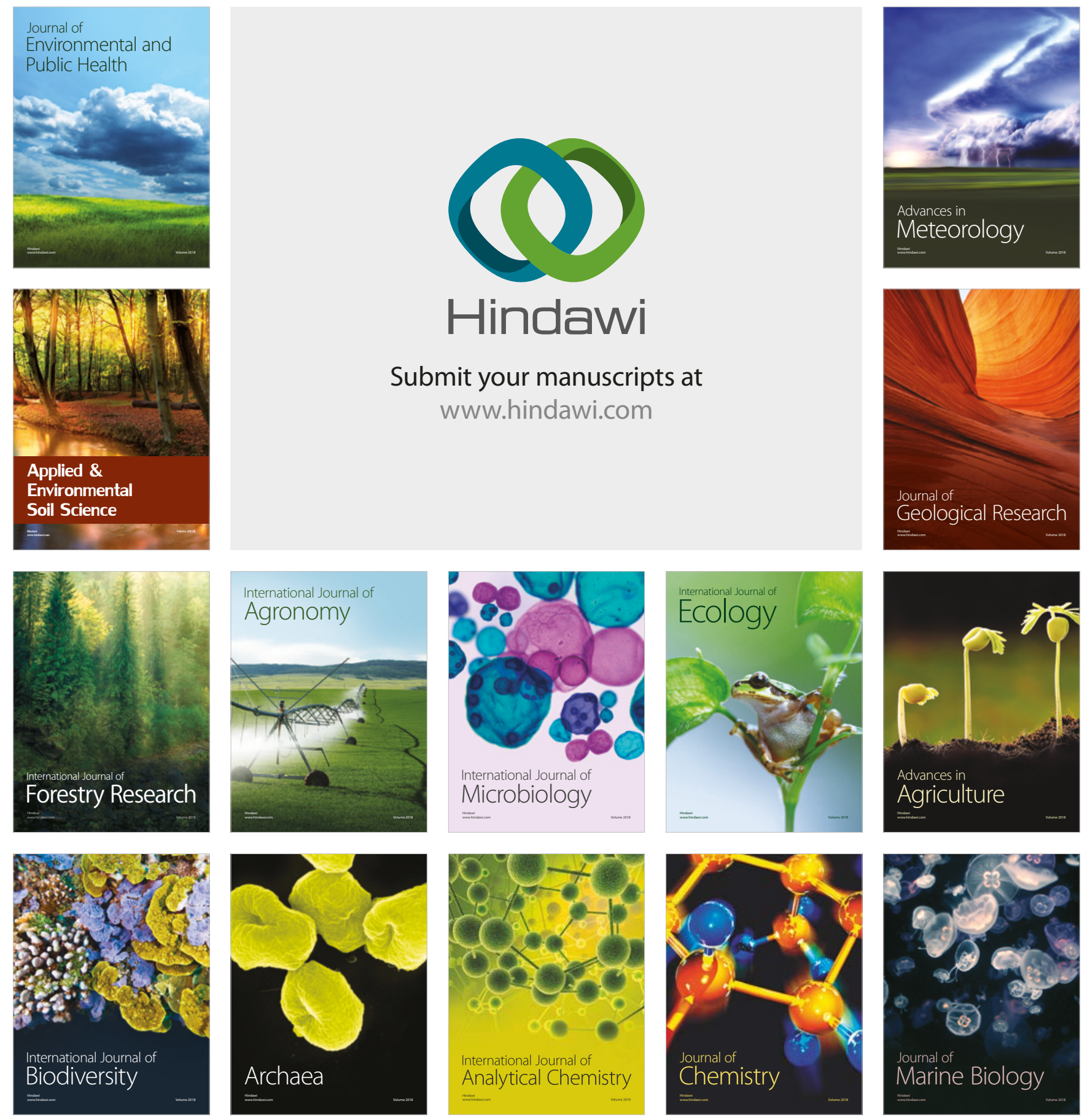